\title{
Acquisition of Complementation ${ }^{1}$
}

\author{
Lois Bloom, Matthew Rispoli, Barbara Gartner, and Jeremie Hafitz
}

CitATiOn: Bloom, L., Rispoli, M., Gartner, B., and Hafitz, J. (1989). Journal of Child Language, 16, 101-120. Reprinted in Bloom, L. (1991). Language development from two to three, New York: Cambridge University, pp. 312-332.

\begin{abstract}
This study concerns the acquisition of complex sentences with perception and epistemic verbs that take a second verb in their complements. The acquisition of complementation began between two and three years of age in this longitudinal study of four children's spontaneous speech. The results of the study showed that (1) complement types and complementizer connectives and (2) the discourse contexts in which complementation occurred were specific to individual matrix verbs. The most frequent verbs acquired were the perception verbs see and look and the epistemic verbs think and know. Developments in both discourse and syntax indicated that these verbs expressed attitudes of certainty/uncertainty toward the content expressed in their complements. The results are discussed in terms of both linguistic and psychological factors in the acquisition of complex sentences with complementation.
\end{abstract}

The study reported here is part of a larger investigation into the acquisition of complex sentences by four children between two and three years of age. We have defined complex sentences in child speech as sentences with two verbs that express two propositions (Bloom, Lahey, Hood, Lifter, \& Fiess, 1980). Complementation is the special instance of complex sentences in which one proposition serves as an argument within another proposition (see also the definitions in Quirk, Greenbaum, Leech, \& Svartvik, 1972). Those complement-taking verbs that take the to complementizer (e.g., want to and have to) were the subject of an earlier report (Bloom, Tackeff, \& Lahey, 1984). For the purposes of the present study, all the remaining complement-taking verbs that this same group of children learned in this period were examined. Verbs were identified as complement-taking verbs if (1) they could take sentential complements (e.g., "think I can put him in a house") or (2) they could take $w h$-complementizers with null arguments (e.g., "Look at what the little bear's eating").

Complement-taking verbs are developmentally interesting for both linguistic and psychological reasons. Linguistically, they provide the first forms of complex sentences in child speech after the acquisition of simple sentences and questions (Limber, 1973; Bloom, Lahey, Hood, Lifter, \& Fiess, 1980; Pinker, 1984). Psychologically, these verbs name internal mental states rather than actions and, moreover, the mental states they name are directed toward actions or other internal states. The emergence of complementation in child speech is, then, a qualitative development in both linguistic and psychological complexity. The purpose of this study was to investigate factors that contribute to this development.

\section{SUBJECTS AND PROCEDURES}

Transcripts of the naturally occurring speech of four children, annotated with descriptions of context and relevant activity, were examined for evidence of (1) the developing productivity of complement-taking verbs; (2) their discourse contexts; and (3) the surface structures of sentences with matrix verbs, including complement type and complementizer connectives.

${ }^{1}$ The research reported here was supported by Fellowship F1-MH-30,001, 1965-1968, from the National Institute of Mental Health; Research Grant HD 03828, 1971-1974, from the National Institute of Child Health and Development; and Research Grants from the National Science Foundation, 1975-1989, to Lois Bloom. This study was published originally in the Journal of Child Language, 16, 1989, 101-20; reprinted in Bloom, L. (1991). Language development from two to three, New York: Cambridge University, pp. 312-332; and reformatted for this digital version with slight changes in organization and minor text editing. 


\section{The Children}

The four children-Eric, Gia, Kathryn, and Peter-were born in the 1960s, the first-born children of white, collegeeducated parents who lived in university communities in New York City. Their parents were native speakers of American English and their mothers were their primary caregivers. They were chosen as subjects with these qualifications in what turned out to be, in retrospect, a naive effort to come up with a 'homogeneous' population. Since parent education, birth order, and economic differences among children had been found to be sources of individual differences in speech and language in other studies, these were the minimal 'controls' that seemed feasible to ensure that the children would be similar in their language learning. ${ }^{2}$

Eric, Gia, and Kathryn were each visited in their homes for approximately eight hours, over several days, every six weeks; Peter was visited for approximately six hours every three weeks. The visits occurred in the context of their daily activities and informal play with a familiar adult (the investigators) and, less often, with their mothers. The same or similar toys were brought to all the sessions, for the different children and for each child, in an effort to establish consistency in the home contexts among the children and over time. The observations were audio recorded, and the transcriptions included all speech by child and adult, along with descriptions of nonlinguistic context and behavior. ${ }^{3}$

For the present study, data are reported for Eric, Gia, and Kathryn from five observation sessions, each lasting approximately 8 hours, at 6-week intervals. For the fourth child, Peter, observation sessions were shorter with 1month intervals between sessions, and data are reported from seven observation sessions. A summary description of the children in terms of age and mean length of utterance (MLU) is presented in Table 1. In this and subsequent tables and figures, Times 1 and 2 represent a grouping of the data on the basis of MLU, for the purpose of identifying developmental trends. The MLU criterion for distinguishing between Times 1 and 2 was 3.5 morphemes (or its closest equivalent).

Table 1. Age and Mean Length of Utterance for Two Developmental Times

\begin{tabular}{|c|c|c|c|c|c|c|}
\hline \multirow[b]{2}{*}{ Child } & \multirow[b]{2}{*}{ Time $^{\mathrm{a}}$} & \multirow{2}{*}{$\begin{array}{c}\text { Number of } \\
\text { Sessions }\end{array}$} & \multicolumn{2}{|l|}{ Age } & \multicolumn{2}{|c|}{ MLU(Morphemes) } \\
\hline & & & Range & Mean & Range & Mean \\
\hline \multirow[t]{2}{*}{ Eric } & 1 & 3 & $2 ; 1.1-2 ; 5 \cdot 3$ & $2 ; 3.1$ & $2.63-3.45$ & 2.97 \\
\hline & 2 & 2 & 2;9.0-3;0.0 & $2 ; 10.2$ & $3.49-4.21$ & 3.85 \\
\hline \multirow[t]{2}{*}{ Gia } & 1 & 3 & $2 ; 1.2-2 ; 4.2$ & $2 ; 3.2$ & $2.30-3.07$ & 2.71 \\
\hline & 2 & 2 & $2 ; 6.0-2 ; 10.2$ & $2 ; 8.1$ & $3.64-3.71$ & 3.68 \\
\hline \multirow[t]{2}{*}{ Kathryn } & 1 & 3 & $2 ; 0.2-2 ; 5.1$ & $2 ; 2.3$ & $2.83-3.35$ & 3.16 \\
\hline & 2 & 2 & $2 ; 8.1-2 ; 11.1$ & $2 ; 9.3$ & $3.70-4.23$ & 3.97 \\
\hline \multirow[t]{2}{*}{ Peter } & 1 & 3 & $2 ; 3.0-2 ; 6.0$ & $2 ; 4.2$ & $2.63-2.90$ & 2.75 \\
\hline & 2 & 4 & $2 ; 7.2-3 ; 2.0$ & $2 ; 10.2$ & $3.05-3.58$ & $3 \cdot 37$ \\
\hline
\end{tabular}

aTimes 1 and 2 are the result of grouping data, with Time $1=\mathrm{MLU}<3.5$, and Time $2=$ MLU $>3.5$.

\section{Complement-Taking Verbs}

The sentences analyzed for this study represented only .007 of all the utterances that the children produced in these sessions between 2 and 3 years of age. The four children produced approximately 79,000 utterances all together. All instances of verbs that could take complements were extracted from the corpus whether or not they

2 However, see Bloom (1992) for a later appraisal of this decision.

3 The procedures for data collection and transcription are described in greater detail in Bloom (1970, pp. 234-9). See, also, Bloom, Lightbown, and Hood (1975) and conventions for transcription of child language recordings, App. A, in Bloom \& Lahey (1978). The speech samples from Eric, Gia, and Kathryn were collected and transcribed by Lois Bloom. The speech samples from Peter were collected and transcribed by Lois Hood and Patsy Lightbown who took turns interacting with Peter and taking notes on the situational context and behavior. The transcriptions of the Eric, Gia, Kathryn, and Peter data are stored for access by other researchers in the Special Collections at the Gottesman Memorial Libraries, Teachers College, Columbia University; transcripts of the Peter data are also part of the CHILDES database, the Child Language Data Exchange System, Carnegie-Mellon University. 
occurred with complements and/or complementizer connectives. In all, over 6,00o sentences with such verbs occurred. The acquisition of those verbs that take to complements was described in another study (Bloom, Tackeff, \& Lahey, 1984). The remaining verbs that could take S- or $w h$-complements and were used in the speech of all four children are the subject of this study: think, know, see, and look (at). Approximately 2,600 sentences occurred with these verbs, and in 577 of these sentences the verbs occurred as matrix verbs with complements.

All the complement-taking verbs in the four children's speech are listed in Table 2 along with the number of children who used each of the verbs productively. Productivity was defined as three different sentences with a particular matrix verb in a single observation session. The verbs are categorized here according to their superordinate meaning. Four verbs were chosen for analysis in the present study (think, know, see, and look (at)4) because these were the only matrix verbs that were productive in the speech of all the children (except the volition-intention verbs that take to complements). These same four verbs were also reported in descriptions of the acquisition of complementation in child speech by Limber (1973) and Pinker (1984).

Table 2. Lexical Categorization of Complement-taking Verbs ${ }^{\mathrm{a}}$

\begin{tabular}{|c|c|c|c|c|c|}
\hline & Perception & Epistemic & $\begin{array}{l}\text { Volition/ } \\
\text { Intention }^{b}\end{array}$ & $\begin{array}{l}\text { Commun } \\
\text {-ication }\end{array}$ & Causative \\
\hline Four children & $\begin{array}{l}\text { see } \\
\text { look (at) }\end{array}$ & $\begin{array}{l}\text { think } \\
\text { know }\end{array}$ & $\begin{array}{l}\text { want } \\
\text { like } \\
\text { go } \\
\text { have }\end{array}$ & & \\
\hline At least two children & $\begin{array}{l}\text { watch } \\
\text { show }\end{array}$ & - & $\begin{array}{l}\text { got } \\
\text { try }\end{array}$ & $\begin{array}{l}\text { say } \\
\text { tell }\end{array}$ & $\begin{array}{l}\text { let } \\
\text { make }\end{array}$ \\
\hline One child & - & $\begin{array}{l}\text { forget } \\
\text { wonder } \\
\text { remember } \\
\text { bet } \\
\text { mean } \\
\text { afraid } \\
\end{array}$ & need & - & $\begin{array}{l}\text { help } \\
\text { get }\end{array}$ \\
\hline
\end{tabular}

\section{RESULTS}

The first result in the child data is the distribution of the epistemic and perception verbs, with and without complement structures. The subsequent results concern only the sentences with complementation and consist of (1) their discourse contingencies and (2) the subcategorization of complement types, complementizer connectives, and cooccurrence restrictions. As will be seen, these subcategorization phenomena in the course of the children's acquisition were not always consistent with the target language they were learning.

\section{Distribution of Verbs}

The frequency with which each verb occurred, both with and without complementation, is presented in Table 3. The perception verbs occurred with complements, on average, $12.5 \%$ of the time (see, 14\%; look, 10\%). Examples of perception verbs without complements were

4Sentences with look were not included in the analyses if (1) they were spoken with segmentation prosody to indicate a sentence break after the matrix verb and/or (2) the sentence complement was a complete sentence with no null constituents (e.g., "Look, my truck got a top"). In both instances, the data were equivocal as to complementation, inasmuch as look was potentially a separate sentence. 
(1) $\mathrm{E} \quad$ Doggie is looking up.

(2) K And nobody can see him.

Examples of these verbs with complements were

(3) G Look what my mommy got me.

(4) $\mathrm{K} \quad$ I'll see where it is.

Table 3. Frequencies of Complement and Noncomplement Sentences

\begin{tabular}{|c|c|c|c|c|c|c|}
\hline \multirow[b]{2}{*}{ Child } & \multirow[b]{2}{*}{ Times } & & \multicolumn{2}{|c|}{ Perception } & \multicolumn{2}{|c|}{ Epistemic } \\
\hline & & & see & look & know & think \\
\hline \multicolumn{7}{|l|}{ Eric } \\
\hline & 1 & + COMP & 15 & 13 & 6 & 12 \\
\hline & & - COMP & 349 & 161 & 4 & 2 \\
\hline & 2 & $+\mathrm{COMP}$ & 53 & 8 & 27 & 42 \\
\hline & & - COMP & 96 & 119 & 68 & 5 \\
\hline \multicolumn{7}{|l|}{ Gia } \\
\hline & 1 & + COMP & 1 & 9 & 1 & 7 \\
\hline & & - COMP & 115 & 27 & 4 & 3 \\
\hline & 2 & + COMP & 23 & 10 & 11 & 5 \\
\hline & & - COMP & 77 & 58 & 14 & 1 \\
\hline \multicolumn{7}{|c|}{ Kathryn } \\
\hline & 1 & + COMP & 23 & 7 & 7 & 30 \\
\hline & & - COMP & 174 & 40 & 1 & 4 \\
\hline & 2 & $+\mathrm{COMP}$ & 45 & 4 & 9 & 44 \\
\hline & & - COMP & 223 & 37 & 4 & 41 \\
\hline \multicolumn{7}{|l|}{ Peter } \\
\hline & 1 & $+\mathrm{COMP}$ & 17 & 3 & 20 & 3 \\
\hline & & - COMP & 165 & 63 & 6 & 5 \\
\hline & 2 & + COMP & 30 & 8 & 49 & 35 \\
\hline & & - COMP & 87 & 89 & 16 & 4 \\
\hline & Totals & $+\mathrm{COMP}$ & 207 & 62 & 130 & 178 \\
\hline & & - COMP & 1286 & 594 & 117 & 65 \\
\hline
\end{tabular}

See was the most frequent perception verb overall; although see occurred only $14 \%$ of the time with a complement, it was the most frequent matrix verb with complements in the corpus.

Epistemic verbs appeared with complements, on average, $64 \%$ of the time (know, 44\%; think, 83\%). Examples of epistemic verbs without complements included routine phrases like "I don't know," "You know?," "I think so," and "Think so?" but also

(5) E I don't know that part.

(6) $\mathrm{K} \quad$ I think up on this bed.

Examples of epistemic verbs with complements were

(7) $\mathrm{P} \quad$ Know what the other ones do?

(8) G I think the children go to bed.

Thus, except for their routine phrases (e.g., "I don't know") these children used the epistemic verbs largely as complement-taking verbs. 


\section{Discourse Environment}

All sentences with complement clauses were examined for evidence of discourse contingency. For this study, contingency was defined as the adult's having said something within five prior speaker turns that included either the matrix verb or part of the complement of the child utterance. These two sources of contingency were not mutually exclusive. A sentence could have been said by a child when the adult had already said a sentence with that matrix verb, or some part of the adult's sentence could have become a part of the complement in the child's sentence, or both these things could have happened.

For example, the children's sentences were contingent when an adult utterance introduced a verb or argument that appeared subsequently in the complement of the child sentence, for example:
(9) Adult: Let's see how this one works.
$\mathrm{K}$ You know how it works?

The frequency with which the complement in the children's sentences included something from a prior adult utterance is presented in Figure 1. Complements with think repeated something from a prior utterance most often (66\% on average); sentences with look (at) did so the least (16\% on average).

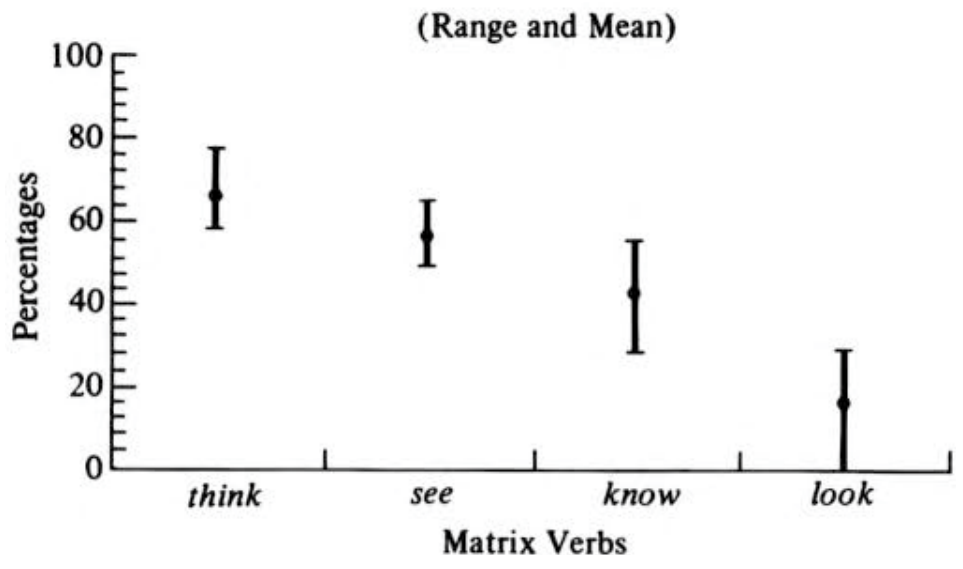

Figure 1. Complement Contingency

Discourse contingency also included the child's use of a matrix verb when the matrix verb had been used by an adult in a prior utterance, for example:

(10) Adult: I think that lamb is cold. $\quad$ E $\quad H e$ is very cold/I think I can put him in a house.

The matrix verb think was repeated from a prior adult utterance more often than any other matrix verb. On average, think had prior adult introduction into discourse $32 \%$ of the time and see $11 \%$, while know and look (at) had prior adult use only occasionally.

We interpret these results to mean that think was most likely to maintain the discourse topic, while look (at) was most likely to introduce a new topic. However, this conclusion is not independent of a second conclusion, that hearing the matrix verb and/or some part of what the child would say also made it more likely that the child would use a matrix verb with complementation. Think, the verb that was most frequently contingent, was also the matrix verb with the highest proportion of complementation.

\section{Complementation Structure}

Complement Type. The two complement types were sentential complements (S-complements), for example:

(11) K I see Mommy washing her hands, and $w h$-complements, for example:

(12) K Let's go see where Mommy is. 
The average frequency of verb + complement types is presented for each verb in Figure 2. The development of complementation in this period of time is apparent: Except for sentences with look, complementation was more frequent in Time 2 than in Time 1. However, the production of particular complement types was not independent of the matrix verbs.

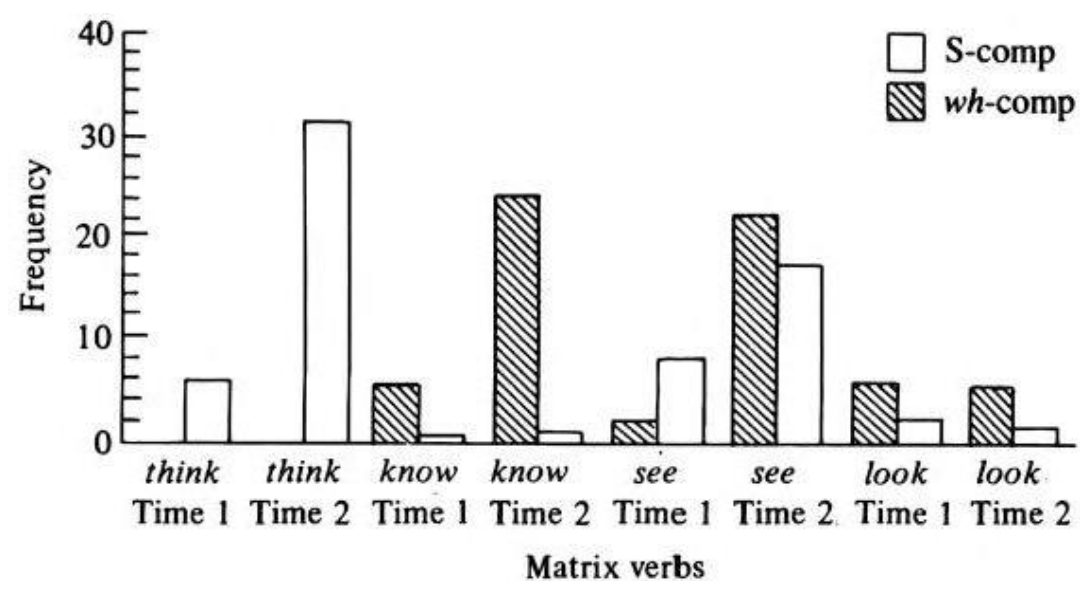

Figure 2. Mean Frequency of complement types

Think appeared only with S-complements (as expected). S-complements occurred more frequently with think than with any other verb for all the children in both time periods. The other epistemic verb, know, appeared almost exclusively with $w h$-complements, for example:

(13) G You know what's in this bag?

and rarely with S-complements, for example:

(14) E I know I open it up.

Both complement types were used with see. Before MLU reached 3.5 (in Time 1), the most frequent complement type with see was sentential, while $w h$-complement sentences were less frequent. Once MLU exceeded 3.5 (in Time 2) the balance was reversed, and wh-complements were more frequent than S-complements. However, this reversal was due almost entirely to one child, Eric. At Time 1, Eric produced $14 \mathrm{~S}$-complements with see, for example:

(15) E I see two bus come there.

and one $w h$-complement sentence. At Time 2 he produced only eight sentences with see and S-complements, and 45 sentences with see and a wh-complement, for example:

(16) E Let's see what's in the train house.

S-complements appeared with look at (15 instances among the four children), for example:

(17) P Look at that airplane coming out the airplane home.

However, in both developmental periods, wh-complements with look (as in (3) Look what my mommy got me, above) were more frequent.

In sum, the two epistemic verbs took different complement types: S-complements occurred with think, and $w h$ complements occurred with know. Overall, wh-complementation was more frequent than S-complements with the perception verbs, especially in Time 2, and S-complements were more frequent with see than with look (at). 
Acquisition of Complementizer Connectives. Wh-complements were not expected with think and were not observed. Otherwise, the complementizers these children learned with know, see, and look (at) were the same words, except for if , that they had acquired earlier in their wh-questions (Bloom, Merkin, \& Wootten, 1982). If, which is not a $w h$-question word, was one of the last of the complementizers they acquired in this period. The order of emergence of $w h$-complementizers resembled the earlier emergence order of $w h$-questions. The two emergence orders are compared in Table 4.

Table 4. Average Age of Emergence for Wh-Question Words and Wh-Complement Words

\begin{tabular}{lllllll}
$\begin{array}{l}\text { Wh-Q } \\
\text { Words }\end{array}$ & $\begin{array}{l}\text { Average } \\
\text { Age }\end{array}$ & $\begin{array}{l}\text { Number } \\
\text { of } \\
\text { Children }^{\mathrm{b}}\end{array}$ & & $\begin{array}{l}\text { Wh- } \\
\text { Comp } \\
\text { Words }\end{array}$ & $\begin{array}{l}\text { Average } \\
\text { Age }\end{array}$ & $\begin{array}{l}\text { Number } \\
\text { of } \\
\text { Children }^{c}\end{array}$ \\
\hline what & $2 ; 2$ & 7 & & & - & - \\
where & $2 ; 2$ & 7 & & - & - & - \\
who & $2 ; 4$ & 7 & & - & - & - \\
- & - & - & & what & $2 ; 6$ & 4 \\
- & - & - & & where & $2 ; 7.2$ & 3 \\
how & $2 ; 9$ & 7 & & how & $2 ; 9.2$ & 3 \\
- & - & - & & (if) & $2 ; 10$ & 4 \\
why & $2 ; 11$ & 7 & & who & $2 ; 11$ & 3 \\
\hline
\end{tabular}

aThe results for $w h$-question words are from Bloom, Merkin, \& Wootten (1982) who included three children in addition to Eric, Gia, Kathryn, and Peter.

${ }^{b} n=7 ;{ }^{c} n=4$.

The emergence age for $w h$-questions in Table 4 is the average for seven children (from Bloom, Merkin, \& Wootten, 1982); the emergence age of the complementizers is an average for four of the same children. In both studies, emergence was considered the beginning of productivity defined as at least three different instances of $w h$-questions, or complements with a particular wh-complementizer, respectively. As can be seen, these children asked what and where questions 4 months (on average) before they used what and where as complementizers. Two complementizers, where and how, reached productivity for three children. How did not become productive in questions until approximately 7 months after what and where questions, but unlike what and where, how emerged as both a question word and a complementizer at about the same time. The last $w h$-word to become productive in the children's questions, why, was not acquired as a complementizer in the period of this study.

Table 5. Distribution, Order of Emergence, and Number of Children ${ }^{a}$ Using the Different Connectives

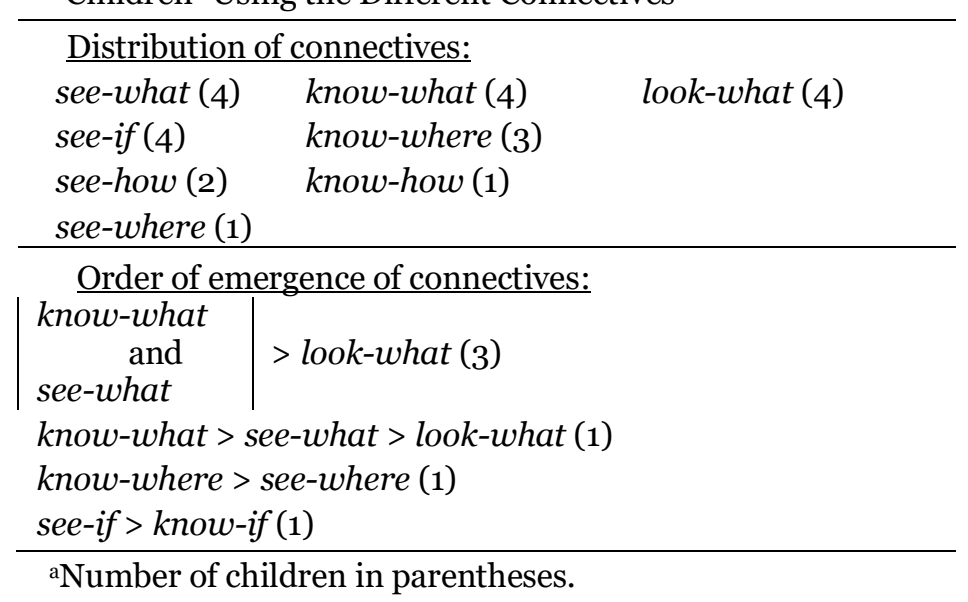

Wh-words are not perceptually salient as complementizers because they occur in the middle of a sentence between the matrix verb and the complement. Their acquisition for complementation may have depended, in part, upon prior segmentation in the more salient, sentence-initial position as $w h$-question words (Pinker, 1984). 
Use of the different complementizer connectives was verb specific. This result is presented in Table 5. Of the three verbs with $w h$-complementizers, only see was productive with all four connectives; know was productive with three; and look (at) was productive only with what. The only wh-complementizer acquired with all the matrix verbs (except think) was what, and what was used by all the children with each of the three verbs that took complementizers. However, the different connectives did not appear at the same time with the different matrix verbs. The order of emergence is presented in Table 5. What was acquired with look (at) only after it had become productive with know and see. Where was productive with know before see, while if was productive with see before know. These results mean that the acquisition of a complementizer did not promptly generalize to all of the children's matrix verbs that could take that complementizer. Rather, these children acquired the complementizer connectives verb by verb.

That was rare as a complementizer in these sentences. A total of 179 complement sentences with think were said by all the children, but only three of these included that as a connective, for example:

(18) G I think that he wanna eat this.

These children certainly knew the word; demonstrative pronouns were among the earliest forms in their simple sentences (Bloom, 1970). In addition, that appeared with other functions in the complements. That appeared 14 times as the subject of the complement verb in the same deictic sentence frame which had been productive from the beginning of these children's multiword speech, for example:

(19) K I thought that was a snacktime.

(20) $\mathrm{E} \quad$ I think that is a porkypine.

In addition, 35 complement sentences occurred with the copula as the matrix verb (not considered in the study reported here), and 25 of these included that as a deictic subject, for example:

(21) E That where the butterfly live.

(22) P That's how get them out.

Although this was frequent as a determiner in the complement subject, only one instance of that occurred in the same position:

(23) $\mathrm{K} \quad$ I think that girl is going to dust that that paper away.

(Note also that Kathryn stumbled on the subsequent use of that in the same sentence.)

Three factors could have contributed to that not being acquired for complementation in the period studied here. First, the plurifunctionality of that may have inhibited its acquisition as a complementizer. Since an item with more than one function within a sentence presumably increases perceptual difficulty (Bever, 1970), we might expect an item with several functions in different sentences to be more difficult to acquire. In this instance, then, the prior acquisition of that with other functions did not facilitate its acquisition as a complementizer, as had been suggested for the acquisition of the plurifunctional $w h$-forms. A second factor is, of course, input frequency. We do not know how often these children heard that as a complementizer with think, know, or see in this time period.

In addition, Jespersen pointed out that complementation without that is especially frequent after such verbs as think, know, and see, but in these cases "it is historically wrong to say that the conjunction that is omitted" (1956/1961, p. 32). Complementation with and without that evolved out of independent sentences, for example, (1) "I think that S" and (2) "I think S." Originally that in (1) was a demonstrative pronoun object of the verb (i.e., "I think that"). The distinction in this historical argument is relevant to these children's development inasmuch as they did not say sentences like "I think that" or "I know that" and also did not use that as a complementizer.

\section{Cooccurrence Restrictions on Matrix and Complement Verbs}

Two features distinguished the surface syntax of the matrix and complement clauses. First, the matrix subjects were highly restricted while the subjects of complement verbs were varied. Second, matrix verbs were rarely inflected whereas the subordinate verb in the complement was often either inflected or marked for modality. 
Subject Restrictions. Certain restrictions would be expected on the matrix verbs studied here. For example, only animate subjects can see, look, think, and know. However, the differences in variety of subjects of the subordinate and matrix verbs were greater than would be predicted by the target language.

Subjects of Subordinate Verbs. The subordinate complement clauses were copular constructions, with pronominal subjects, in an average of $48 \%$ of the sentences with know, $35 \%$ with think, $31 \%$ with see, and $8 \%$ with look (at), for example:

(24) K I think it's big enough.

(25) E Know what's in here?

(26) G I'm going to see if there's any more.

Otherwise, a full variety of first-, second-, and third-person subjects occurred in the complements, both nominal, for example:

(27) E Look at that donkey carrying baskets,

and pronominal, for example:

(28) $\mathrm{K} \quad$ I think we can put it side of him.

Subjects of Matrix Verbs. In contrast, the subjects of matrix verbs were highly restricted. To begin with, no subjects were expressed with look; all were null second person (as in (27)). The matrix verb think occurred only with $I$ in the speech of three of the children. Only Peter, whose earliest and latest sentences with think included only $I$, produced sentences with think in the interim without $I$. Most of these were null first person, but several were null second person, and one second-person subject was expressed:

(29) P You think it don't belongs to me.

The subjects of sentences with know and see were only somewhat more varied, and the order of acquisition differed for the different children. Both Gia and Eric began saying sentences with these two matrix verbs first with first-person $I$, and then with second-person you both expressed and null. Kathryn and Peter both began to say sentences with know and see with null second-person subjects (Kathryn also expressed second-person you) before they used these matrix verbs with $I$. Neither Gia, Kathryn, nor Peter used any of their matrix verbs with third-person subjects. Only Eric eventually used both of these matrix verbs with third-person subjects, for example:

(30) $\mathrm{E} \quad$ Oh the bunny rabbit doesn't know what to do.

In sum, this group of matrix verbs were verbs that named internal mental states and they were acquired to express these states of the child and, to a lesser extent, of the child's discourse partner. They were not used to express the child's attributions of such states to others who were not participants in the discourse (in contrast to the data reported by Shatz, Wellman, \& Silber, 1983). On the one hand, the use of these verbs in the children's speech was consistent with accounts that have described limitations on the preschool child's awareness of the mental states of other persons (e.g., Piaget 1923/1955; Wellman, 1985). On the other hand, the fact that these children did not talk about what third persons see, look at, think, or know is not by itself evidence that they could not attribute these internal states to other persons. By the age of 3 years children are able to attribute seeing and looking to other persons (Flavell, 1978). Mothers of children in the same age range as the children studied here have reported that their children use perception words (and significantly more often than epistemic words) in talking about other persons (Bretherton \& Beeghly, 1982). ${ }^{5}$ Nevertheless, the differences between matrix and subordinate subjects were not entirely predicted by the target language.

Coreference. The children's sentences were examined to determine the coreference of the subject of the complement verb. A total of 332 complements occurred with nominal or personal pronoun subjects, and in only $46(14 \%)$ was the subject of the complement verb coreferent with an expressed subject of the matrix verb. Of

5However, the children in our study did not, in fact, use third-person subjects with these verbs even in their simple sentences without complements. 
these coreferent subjects, $61 \%$ occurred with think, $28 \%$ with see, $11 \%$ with $k n o w$, and none with look (at). Thus when coreferent subjects did occur, these were with think most often, for example:

(31) K I think I'll pull the other side.

Sentences with such volition-intention verbs as want, like, and go were productive with to complements in these children's speech about 2 months earlier than complementation with epistemic and perception verbs (reported in Bloom, Tackeff, \& Lahey, 1984). In sentences with to complements the subject of the matrix verb was also the subject of the complement verb. The children were most often talking about what it was that they wanted to do or were going to do. Non-coreferent subjects appeared in sentences with to after MLU 3.5, and this was after noncoreferent subjects appeared with the epistemic and perception verbs. This sequence of development (from Bloom, Tackeff, \& Lahey, 1984, together with the present study) was the same sequence that Pinker (1984) also observed. Complementation with subject coreference (with to complement verbs and then with think) occurred before complementation with non-coreferent subjects.

Morphological Marking. Matrix verbs and subordinate complement verbs also differed in the extent to which they were inflected and/or marked for modality. Again, this difference was not entirely predicted by the target language.

Matrix Verbs. The restrictions on subjects of matrix verbs and the fact that these verbs were state rather than process verbs limited the opportunities for matrix verb inflection. No inflections occurred with look (at), but none was expected, since look (at) occurred only with second-person subjects in the imperative. Know was limited to either first- or second-person subjects and used frequently with generic copular statements in the complement. Know was never inflected. Think was used almost exclusively with first-person $I$, but only Kathryn used think with past tense (6 instances, e.g., (19) above).

See was used with only first- and second-person subjects and was never inflected. However, see was the one matrix verb that occurred with adverbial or modal marking with any regularity. Twenty-four percent of the sentences with see as a matrix verb also included an adverb (e.g., now) or modal, for example:

(32) P Wanna see I make a ball with my gum?

The children differed in the matrix adverbials and modals used with see. Eric used only let's ((16) above) and now; Gia used gonna and wanna; Kathryn used let's ((12) above); and Peter used wanna ((32) above). While the modals would not be expected with think, they might have occurred with know and look but did not.

Subordinate Verbs. In contrast to the matrix verbs, the subordinate verbs in the complement were inflected or occurred with marked modality more than $50 \%$ of the time. However, subordinate verbs were used with modals primarily in sentences with think and see $(65 \%$ of the modals in complement sentences occurred after think and $29 \%$ after see), for example:

(33) E I think we should put this in a house.

Except for Gia, the children used modals with subordinate verbs after see and most of these (64\% of the modal complement sentences with see) were can after the complementizer if, for example:

(34) K See if it can make some sound.

Together, these results lead to the same conclusion offered above with respect to discourse function, complement type, and selection of complementizer connectives: The syntax of sentences with complements was matrix verbspecific. Different cooccurrence restrictions on verb inflections, modality, and subjects were observed with the different matrix verbs. In addition, the matrix verbs, as a group, were more restricted in their cooccurrence than were the subordinate verbs in the complement.

\section{DISCUSSION}

The results presented here together with the results reported in Bloom, Tackeff, \& Lahey (1984) document the beginning of the acquisition of complementation between two and three years of age. We will discuss these results in terms of two aspects of the acquisition of complementation with perception and epistemic verbs: the use of 
developmentally prior linguistic forms for acquiring the syntax of complementation, and the meaning function that these complement-taking verbs served in the mental life of the child.

\section{The Origin of the Structures of Complementation}

Both complementizers and complement types were based upon structures previously acquired. The children were ready to produce both S-complement and $w h$-complement structures in the first developmental period of this study because they already knew their basic surface structures from earlier learned sentence frames. As observed originally by Limber, "complex sentences will be formed from the child's repertoire of simple sentences" (1973, p. 184).

S-complementation was essentially the addition of a simple sentence after a matrix verb. Sentences with $w h$ complements consisted of a wh-question word and a sentence with elision of the element corresponding to the question word. The syntax of $w h$-complements was the same as the syntax of early $w h$-questions. When children first begin to ask $w h$-questions, they often start the questions with a $w h$-word and add a simple sentence (e.g., "What you doing?" and "Where the ball go?"). Similarly, when these children began to produce $w h$-complements, they added the matrix verb to a wh-question (e.g., "See what you doing" and "Know where the ball go"). Interestingly, 'errors' like "I don't know what's his problem" are found even among adults (Fay, 1980, p. 117). Thus the developmental origins of both S-complements and $w h$-complements were in the structures acquired at an earlier time for simple sentences and asking $w h$-questions.

However, this process of acquisition consisted of more than the simple addition of forms. For example, while certain cooccurrence restrictions on matrix verbs could have been expected (e.g., lack of tense inflections with second-person subjects in the imperative), others were not (e.g., the lack of modals with subordinate verbs after know and look, or the occurrence of adverbs and modals in the matrix only with see, or the limitations on the subjects of all the matrix verbs). Two factors could explain this pattern of results. One explanation might have been found in the input that the children received, and this is a subject for future research. In addition, however, evidence from psycholinguistic studies of sentence processing has suggested that complement-taking verbs are inherently more difficult than simple transitive verbs for adults to process (Fodor, Garrett, \& Bever, 1968). Children might therefore be expected to have greater difficulty in learning cooccurrence restrictions with complement-taking verbs than with the earlier learned transitive and intransitive verbs that appeared as subordinate verbs in complements.

The acquisition of complementation builds on prior acquisition of simpler structures in yet another way. The acquisition of wh-complementizers followed their prior segmentation in the more salient sentence-initial question frames. To acquire a word as a complementizer requires that "the word in question must be isolated as a word beforehand" (Pinker, 1984, p. 227). Wh-complementizers appeared originally as wh-question words. However, the complementizer to was segmented as a preposition when it was also acquired as a complementizer (Bloom, Tackeff, \& Lahey, 1984). When to did appear as a complementizer, with volition-intention verbs, it was not semantically empty. Rather, to had the meaning "direction toward" which derived historically from the prepositional meaning. A related analysis to demonstrate that the "complementizers $(f o r, t o)$ [are] identical to prepositions" has since been reported with for, which was first used as a complementizer only with purposive meaning (Nishigauchi \& Roeper, 1987, p. 91). ${ }^{6}$ The categorization of a word as a complementizer may be 'given' along with its categorization as a preposition (Pinker, 1984, p. 226). However, we would suggest instead that the knowledge that a word can also be a complementizer is acquired from observing the distributional regularities of matrix verbs with relevant complementizer connectives in the input. Thus one reason why that, which was one of the children's earliest and most frequent words, was not acquired as a complementizer in the period studied here, was its perceptual confusability. That was learned with several different functions in sentences with matrix verbs.

In sum, the acquisition of complementation began for the four children whom we have studied between their second and third birthdays. This acquisition no doubt continued well into their school years as they learned more different verbs that take complements and more of the lexical, discourse, and syntactic functions of those verbs.

${ }^{6}$ We thank Richard Beckwith for calling this analysis to our attention. 


\section{The Meaning Function of Complement-Taking Verbs}

These children acquired the structures of complementation with only a handful of the possible verbs that take complements in adult English (Rosenbaum, 1967). Moreover, the majority of the verbs acquired (in Table 1) expressed two superordinate meanings; they were epistemic verbs (e.g., think and know) and perception verbs (e.g., see and look (at)) primarily.

A pattern of lexicalization for the verbs of perception in a sample of 53 languages has been reported by Viberg (1984), with lexical differentiation of the five sensory modalities-sight, hearing, touch, taste, and smellhierarchically organized in a typology. The hierarchy is manifested in the extent to which different words name the activity and experience dimensions in each modality. The modalities of sight and hearing in these languages most often have different lexicalizations for activity and experience. In English, for example, the activity verbs are look and listen, and the experience verbs are see and hear for sight and hearing, respectively. The modalities of touch, taste, and smell show differentiation between activity and experience much less often, English being an example of a language that does not lexicalize these distinctions (e.g., taste in English names both the activity and the experience).

Languages that differentiate activity and experience for only one of the modalities of sight and hearing do so in the sight modality rather than hearing. Sight verbs, then, are at the top of the lexicalization hierarchy for perception verbs, and correspondingly the children in this study differentially lexicalized only sight verbs with complementation. The sight verbs in the speech of all four children were the two basic sight verbs cited by Viberg, look (activity) and see (experience). Although one or more of the children also acquired other complement- taking perception verbs (in Table 1), these were also sight verbs (i.e. the activity verbs watch and show). The beginning acquisition of complement-taking verbs was thus consistent with the lexicalization hierarchy found for the languages studied by Viberg (1984).

While a similar typology is not available, to our knowledge, for epistemic verbs, the two epistemic verbs the children acquired also distinguished between the activity (think) and the experience (know). Think and know were also the most frequent epistemic verbs by far in the longitudinal data reported by Shatz, Wellman, \& Silber, (1983).

While few studies have looked at the uses of such verbs in spontaneous speech, several experimental studies of the comprehension of epistemic verbs have been reported with children as young as three years of age (e.g., Johnson \& Maratsos, 1977; Abbeduto \& Rosenberg, 1985). The conclusion in these studies was that 3-year-olds do not present evidence in comprehension tasks that they understand the differences in the psychological meaning entailments in the terms think and know. Such understanding was not reported in these studies until age 4. However, in the pattern of results presented here, the 2 year old children whom we studied used these two verbs differently. Moreover, the differences in use suggested that they used these verbs to express an assessment of the "degree of reliability" (Chafe, 1986) of the proposition expressed in the complement of their sentences with think and know.

The children seemed to have learned think and know in order to qualify the degree of 'certainty-uncertainty' of the complement propositions in their sentences. The expression of uncertainty with think was suggested by the following findings: (1) Think was most often contingent on prior discourse, suggesting that the children were expressing new information from the prior discourse that they had not yet fully assimilated (Choi, 1986). (2) The frequent use of modals (e.g., should, can) with the verbs in complements of think expressed a lack of definiteness in the complement. (3) The complementizer that, which indicates certainty with think (Jespersen, 1956; Quirk, Greenbaum, Leech, \& Svartvik, 1972), was almost entirely absent from the children's sentences with think. Likewise, Limber (1973, p. 185) citing Urmson (1963), observed that think was "used parenthetically, especially in the first person, $I$, with the sense of perhaps or maybe."

A pattern of certainty for know was suggested by other findings. (1) Less contextual and textual contingency occurred with know than with think, indicating that sentences with know expressed what the children already had in mind and were prepared to introduce into the discourse. (2) Know occurred most often with the copula as the subordinate verb in the complement, suggesting talk about attributions and generic events. These children, 
then, differentiated the epistemic verbs with respect to their assessment of the degree of certainty regarding the complement propositions.

Similar attitudinal distinctions could be attributed to the use of the perception verbs look and see, and see was similar to think in expressing uncertainty. See was second only to think in the extent to which the children's sentences repeated something from the prior discourse. See was second only to think in the frequency of modals in the complement and the only one of the matrix verbs used with modals and adverbs. And finally, see occurred with the conditional connective if and never with the definite that. Look, in contrast, suggested an attitude of definiteness or certainty; it was used exclusively with second-person subjects as an imperative and was contingent on prior discourse least often among all the matrix verbs.

The attitudinal distinctions expressed through the different matrix verbs are best represented by think and look, the two matrix verbs that were the most clearly differentiated: (1) in their superordinate meaning (epistemicperception), (2) in their functions (first-person statements/ second-person imperatives), and (3) in the extent to which they incorporated elements from the prior discourse. Think expressed the child speaker's uncertainty and continued a topic introduced into the discourse most often by someone else. Look expressed a directive to the hearer and introduced a new topic that originated with what the child had in mind. Know and see were intermediate between these two verbs, with know closer to look in expressing certainty and see closer to think in expressing uncertainty. This lexical patterning suggests an intricacy in the emerging verb lexicon, derived from the child's view of the world, that has both discourse and syntactic manifestations. It also supports the suggestion that the acquisition of internal state verbs begins with an effort to modify the reliability of statements before the truly cognitive meanings of the terms are acquired (Johnson, 1982).

\section{CONCLUSIONS}

The conclusions we draw from these results are consistent with those we have drawn in other studies of these children's language development: Learning the structure of the language is verb dependent (e.g., Bloom, 1981; Bloom, Miller, \& Hood, 1975). The study reported here, together with the earlier study of to, revealed developments in the subcategorization of complement structures by matrix verbs. The earlier learned volitionintention verbs have the inherent meaning "direction toward" and take complements with to (Bloom, Tackeff, \& Lahey, 1984). Epistemic and perception verbs, learned later, take S- and wh-complements. The acquisition of the syntax of complementation was lexically specific. Rather than learning a general rule for complementation per se, or even separate rules for wh-complements, S-complements, to complements, if complements, and so forth, the children's grammatical knowledge was specific to the matrix verbs. The matrix verbs determined whether a complementizer occurred and, if a complementizer occurred, which one. In the period studied here the children learned this for each matrix verb separately.

This developmental account is consistent with the procedures Pinker proposed for the acquisition of Lexical Function Grammar, whereby children learn that "matrix verbs specify the formal properties of their complements, such as being finite or infinitival, and whether and which complementizers must be present in the complements" (1984, p. 213). However, in addition, we have proposed that procedures for acquisition are influenced by the psychological attitudes that children have toward the propositions they express. In sum, the acquisition of complementation depends upon the child being able to hold in mind two propositions, where one of the propositions is expressible in a simple sentence frame and the other is the mental attitude directed toward the contents of that proposition. 


\section{REFERENCES}

Abbeduto, L., \& Rosenberg, S. (1985). Children's knowledge of the presuppositions of know and other cognitive verbs. Journal of Child Language, 12, 621-41.

Bever, T. (1970). The cognitive basis for linguistic structures. In J. Hayes (Ed.), Cognition and the development of language (pp. 279-352). New York: Wiley.

Bloom, L. (1970). Language development: Form and function in emerging grammars. Cambridge, MA: MIT Press.

Bloom, L. (1981). The importance of language for language development: Linguistic determinism in the 1980s. In H. Winitz (Ed.), Native language and foreign language acquisition (vol. 379, pp. 160-71). New York: New York Academy of Sciences.

Bloom, L. (1992). Racism in developmental research. President's Message, Division 7 Newsletter. Washington, DC: American Psychological Association, Fall-Winter.

Bloom, L., \& Lahey, M. (1978). Language development and language disorders. New York: Wiley.

Bloom, L., Lahey, M., Hood, L., Lifter, K., \& Fiess, K. (1980). Complex sentences: Acquisition of syntactic connectives and the semantic relations they encode. Journal of Child Language, 7, 235-61.

Bloom, L., Lightbown, P., \& Hood, L. (1975). Structure and variation in child language. Monographs of the Society for Research in Child Development, 40 (serial no. 160).

Bloom, L., Merkin, S., \& Wootten, J. (1982). Wh-questions: Linguistic factors that contribute to the sequence of acquisition. Child Development, 53, 1084-92.

Bloom, L., Miller, P., \& Hood, L. (1975). Variation and reduction as aspects of competence in language development. In A. Pick (Ed.), Minnesota symposia on child psychology (vol. 9, pp. 3-55). Minneapolis: University of Minnesota Press.

Bloom, L., Tackeff, J., \& Lahey, M. (1984). Learning to in complement constructions. Journal of Child Language, 10, 391-406.

Bretherton, I., \& Beeghly, M. (1982). Talking about internal states: The acquisition of an explicit theory of mind. Developmental Psychology, 18, 906-21.

Chafe, W. (1986). Evidentiality in English conversation and academic writing. In W. Chafe \& J. Nichols (Eds.), Evidentiality: The linguistic coding of epistemology (pp. 261-72). Norwood, NJ: Ablex.

Choi, S. (1986). Pragmatic analysis of Korean modal markers in children's speech. Paper presented to the Annual Meeting of the Linguistic Society of America, New York.

Fay, T. (1980). Transformational errors. In V. Fromkin (Ed.), Errors in linguistic performance: Slips of the tongue, ear, pen and hand (pp. 111-122). New York: Academic Press.

Flavell, J. (1978). The development of knowledge about visual perception. In C. Keasey (Ed.), Nebraska symposium on motivation 1977: Social cognitive development (vol. 25, pp. 43-76). Lincoln: University of Nebraska Press.

Fodor, J., Garrett, M., \& Bever, T. (1968). Some syntactic determinants of complexity, II: Verb structure. Perception and Psychophysics, 3, 453- 61.

Jespersen, O. (1961). A modern English grammar on historical principles (vols. 1-7). London: Allen \& Unwin. (Originally published between 1909 and 1949)

Johnson, C. (1982). Acquisition of mental verbs and the concept of mind. In S. Kuczaj (Ed.), Language development (vol. 1, pp. 445-78). Hillsdale, NJ: Erlbaum.

Johnson, C., \& Maratsos, M. (1977). Early comprehension of mental verbs: think and know. Child Development, $48,1743-7$. 
Limber, J. (1973). The genesis of complex sentences. In T. Moore (Ed.), Cognitive development and the acquisition of language (pp. 169-85). New York: Academic Press.

Nishigauchi, T., \& Roeper, T. (1987). Deductive parameters and the growth of empty categories. In T. Roeper \& E. Williams (Eds.), Parameter setting (pp. 91-121). Dordrecht: Reidel.

Piaget, J. (1923/1955). The language and thought of the child. London: Ke gan Paul.

Pinker, S. (1984). Language learnability and language development. Cambridge, MA: Harvard University Press.

Quirk, R., Greenbaum, S., Leech, G., \& Svartvik, J. (1972). A grammar of contemporary English. London: Longman Group.

Rosenbaum, P. (1967). The grammar of English predicate complement constructions. Cambridge, MA: MIT Press.

Shatz, M., Wellman, H., \& Silber, S. (1983). The acquisition of mental verbs: A systematic investigation of the first reference to mental state. Cognition, 14, 301-21.

Urmson, S. (1963). Parenthetical verbs. In C. Caton (Ed.), Philosophy and ordinary language (pp. 220-40). Urbana: University of Illinois Press.

Viberg, A. (1984). The verbs of perception: A typological study. In B. Butterworth, B. Comrie, \& O. Dahl (Eds.), Explanations for language universal (pp. 123-49). Berlin: Mouton.

Wellman, H. (1985). The child's theory of mind: The development of conceptions of cognition. In S. Yussen (Ed.), The growth of reflection in children (pp. 169-206). San Diego: Academic Press. 